\title{
MANAGING CHANGES IN DEVELOPING WORLD: CASE STUDIES OF BLENDED LEARNING ADOPTION (CHANGE) IN CAMBODIAN HIGHER EDUCATION INSTITUTIONS
}

\author{
Ratana SOM ${ }^{a}$, Raksmey CHAN ${ }^{b}$, Dănuț Dumitru DUMITRAȘCU ${ }^{c^{*}}$ \\ ${ }^{a, b}$ Royal University of Phnom Penh, Cambodia \\ ${ }^{c}$ Lucian Blaga University of Sibiu, Romania
}

\begin{abstract}
A conceptualization of change management framework informed that positive change is managed with considerations of type, elements and process. This framework was confirmed by recent situational analyses made at two Cambodia's public higher education institutions where adoption of Blended Learning (the change) was found to be promising with increased students' satisfaction, increased lecturers' involvement and continued program expansion. Employing case study design, this study aims to reconfirm the constructs, suggesting, where possible, for readjustment to make it really works. To that end, in-depth interviews with institutional leadership and key informants and focus group discussion with involved faculties were conducted. Results from the study suggested that although the framework do explain the real management practices on the ground, it had been deformed in a way that allowed the above top management much bigger control on type and elements of change. Middle managements (the Center's head) whose roles were supposed to have the above controls were left otherwise to manage the whole process of change. While this strategic error, on the one hand, made the above successes far from being institutionalized, it, on the other hand, confirmed the validity of the above framework. For this framework to be most practical, this study recommends that more strategic supports and policies, together with a reliable monitoring and evaluation platform, be developed while internal source of funding should also be secured.
\end{abstract}

KEYWORDS: blended learning, change management, developing world, higher education institutionalization, institutions.

DOI: 10.24818/IMC/2021/03.07

\section{INTRODUCTION}

Drive to embrace technology for professional development is more critical in this generation, than any other (Franklin, 2015; Nyandiere, 2006). In education, technology adoption has expanded from administrative affairs to even teaching and learning. Studies which were previously taken place at school now can be accessed virtually either in forms of Blended Learning (BL-the integration of online and face-to-face learning) or even pure online learning. Teachers are no longer classroom controllers but mere facilitators or organizers while students become more independent as they can learn at any time and from anywhere without having to commute to physical classroom (HewittTaylor, 2003; Wheeler, 2001). These shifting paradigms were triggered by the fact that technology, when properly used, could ease the burden and improve performances (Poon, 2013). But yet, adopting technology has also brought about changes. Evident suggests that institutions that are not ready for change, or unable to manage the changes, are failing despite the presence of modern technology (Muluneh \& Gedifew, 2018; Tusubira \& Mulira, 2004). This is particularly obvious in

\footnotetext{
*Corresponding author. E-mail address:dan.dumitrascu@ulbsibiu.ro
} 
the context of developing countries where institutions are generally weak, and the ideal practice of change management has oftentimes been overlooked. According to Khan et al. (2012), many failures of change adoption were caused by the conviction that the change per se does not require much management besides effective technological tools, skills to monitors, and financial supports although such complacency had been earlier warned by Kotter (1996), claiming two-third of change projects failed due to poor and unguided management at the absence of common change model.

In Cambodia, drives for technology adoption into the field of education have largely been witnessed at all level of authorities. With the support from Korean International Agency (KOICA), the government, via Ministry of Post and Telecommunications (MPTC) in 2015, has produced an ICT Master Plan addressing on four main areas, which include, Empowering People, Ensuring Connectivity, Enhance Capabilities and Enriching e-Service (Koica, 2014).

In Higher Education Institutions (HEIs), new teaching and learning technologies are being embraced as part of the pedagogy; these included, but not limited to, BL, flipped classroom and online-learning. Capacity development for academic staffs and students are also taking into account by the ministry as stated in the education strategic plan 2014-2018 and 2018-2023 (MoEYS, 2010, 2019).

Despite such efforts, obvious success as a result of ICT driven program (change) has yet to be identified at any level of authority as challenges obviously outnumbered positive outcomes. While some raise financial issue as the main challenge, others point to the issue of human capacity, lack of policies and even the absence of effective coordination. At some other instances, the challenges were found to be the unwillingness for change at the side of the institutional leadership, while others point, otherwise, to the force of resistance from the side of the grassroots. To put all these arguments into perspective, none of the above rational is wrong. The challenges are indeed all of them. Mitigating the challenges requires not a case-by-case solution, but a total approach that needs to be systematically managed. To achieve those goals [digital literacy among students and teachers], in-hand supports from the ministry to the public and private HEIs are in dire need and clear direction and standard should be set for this process as well.

Out of the above constraints, glimpses of success were visible from change programs - the adoption of BL-being implemented at two leading public HEIs in Cambodia. Denoted as Institution A (IA), and Institution B (IB), these two institutions managed to show an extent of success which were measured by increased student participations and satisfaction, increased lecturer involvements, and continued program expansion. Yet, the hope for these changes to be institutionalized is still farfetched due to the missing model of effective change management. Since the study on change management in Cambodian context, particularly public higher education institution, is scarce, this study aims to investigate the two cases (IA's and IB's BL change management) in depth as a reflection to the change management framework that researchers have built. Results drawn from these studies will inform change practitioners in general and the managers (of the two institutions) in particular regarding change management practices that work. To ease understanding, the below presentation is started from the situational analysis of the two cases, followed by conceptual framework. Findings drawn from the cases comes next, followed by discussions and a conclusion.

\section{PRESENTATION OF THE CASES AND SITUATIONAL ANALYSES}

\subsection{The Adoption of Blended Learning (Change) at IA}

Change at the IA is reflected in the form of the adoption of BL as a replacement for the traditional face-to-face classroom. It dated back to 2006, when a group of like-minded faculties at the Department of Information and Communication Engineering (known as GIC in French) of the IA introduced BL methodology to some of its regular face-to-face program in 2006. The aim was mainly to liberate some of the physical presences of students and teachers in the classroom through 
the provision of recorded lesson, and distant teacher-student interactions. By doing so, it should, in their views, allow them (the faculties) to use the liberated time for research and development.

Despite some management supports since then, the move was not smooth. It was not until 2011 when available funding from KOICA was disbursed to the IA. With a 1-million-dollar grant, an eLearning Center was substantially upgraded in 2012 to become a separate center under the IA. This Center is put to operate a long side with the existing IT Center, and the GIC whose respective roles were to provide overall technical supports to the IA and to offer the IT-related academic credentials for incumbent students. Unlike these two units, eLearning Center was tasked primarily to develop BL contents for all the departments under the IA. On top of this, the Center was also obligated to build a model for other higher education institutions in the country.

At its official start in 2012, a coalition team was formed by the IA top management. The GIC's head, who was believed to have mature experiences in BL was selected to be also the Head of the new eLearning Center, together with a few specialized staffs. This new taskforce was obligated to execute the change project, which was divided into two phases; the first phase (2012-2015) focused mainly on piloting the operation and location, and the second one (2016-2019) was aimed for the expansion of the model to other local HEIs. To kick off the first phase, the team readied up some important technology elements including the setting up of studio room, contents development room and operation room. Along with that, some twenty staffs (including lecturers, studio engineers, and content developers) from this entity were sent to Korea for a-fortnight training, with hope that upon their returns, those staff would be able to use the available technologies more effectively.

In 2013, a number of instructional videos, and other BL materials were produced by the team under the eLearning Center. Although the produced materials could be widely distributed to the rest of other departments, they were contained only for the GIC where it was designated as a pilot department. The selection of GIC was not by chance, but by the experiences the GIC had with such ICT-assisted teaching and learning. Beginning with only two converted courses under one department (GIC), the program expanded to the second department in the following year. By 2015, it was reported that thirteen courses have been subsequently transformed into BL contents and got successfully introduced to all departments under the IA.

Behind this incremental success, painstaking efforts have been made by both the head of the Center, who took the role as a middle manager, and the IA Director, who was responsible for the creation of the enabling environment for the change. With green light from the Director, the head of the Center took efforts to get the new practice bought in by their ground staff so that resistances could be minimized. This requires the manager to call for frequent meetings to gauge their concerns, offer various trainings to upgrade their capacity, and even get down face-to-face to explain a need for change. For the change to be also accepted by students, the Center offered three levels of human support, which include the provision of instructors, teacher assistants, and the Learning Management System (LMS) administrators and technicians. While the instructors, in this new teaching context, is tasked to provide merely wrap-up lectures and answer students' questions, teacher assistant is tasked to deal with instantaneous problems incurred throughout the process of online learning. Shall the students face the challenges on technicality, including the LMS, they could always refer that to the administrators or technicians who are always responsive.

To help create an enabling environment, remarkable supports were given from the side of IA top management. To encourage staff to adopt change, the management offers some considerable incentives to staff who get themselves involved in the project. The incentive ranges from salary increase, opportunity to get training abroad, and even a chance of promotion. To drive the above stimulus, the management was said to have adopted a number of supporting policies (no formal writing), which include, institution support policy, staff supporting policy, and student support policy. On top of policy support, response on ICT demands by ground staffs (Internet speed upgrade, software update) was seen to be practical although that is hugely subject to available financial resources. 
As a wrap-up for the first phase of project implementation, a survey was conducted among the students in 2015 to see their views on the change program. The result showed that almost all participants expressed positive attitude towards the program, with around $60 \%$ of participants perceived the usefulness of this new learning experience. Approximately $49 \%$ of participants admitted that they did go for additional reading materials after participating in the online courses. Some $40 \%$ of the respondents revealed that they enjoyed doing BL, and that they wanted to take another course like this as it really met their expectation. Many of the respondents are even willing to recommend this new teaching and learning technique to other learners (IA's internal report).

With this substantial success, the program was given a green light in 2016 by the top management of the IA to further proceed to its second phase, which is set to replicate the success model to not only other programs in the Institute, but also to other HEIs within the country. In 2018, the United Nations Educational, Scientific and Cultural Organization (UNESCO), in cooperation with the Ministry of Education Youth and Sport (MoEYS), chose the e-Learning Center of the IA to be a project implementer to develop an online learning contents for the Basic Education Equivalency Programme (BEEP), an online platform allowing the public to access alternative ways to complete lower secondary and basic education using e-learning.

\subsection{The Adoption of Blended Learning (Change) at IB}

Department of English (DoE) is one of the three leading departments of the IB. Currently housed under the Institute of Foreign Languages, DoE was founded in 1985 by the MoEYS, under the auspice of Australian non-governmental organization, Quaker Service Australia (QSA). Initially born as the Cambodian English Language Training Program (CELT), DoE, in 1993, was transformed into Department of English (under the Foreign Language Center, FLC), offering a bachelor's degree program in Teaching English as a Foreign Languages (TEFL). Since its establishment, the DoE has been the leading English language training institution in Cambodia. Its past success has allowed the DoE to currently offer a number of other English-related bachelor degrees, including post-graduate degree program.

The ambition to integrate technology into language teaching and learning has long been the ambition of the management team of the DoE. Yet, with neither financial supports, nor technical assistances from its top management, such ambition has been far from being materialized. A move to adopt BL could only be put into practice in 2017 when the University of Hong Kong, as part of its study on BL integration in the context of the developing country, offered to assist with this new initiative.

Setting up a coalition team was also the first move for DoE management to introduce change. The DoE management, in its monthly meeting, called upon the like-minded lecturing staff who shared the passion to join. They were then convinced to form a change team. No prerequisites, and of course, no previous experiences of using the ICT in teaching were needed. Those who volunteered to join the effort will be given some informal peer-to-peer trainings on the use of technology. With three volunteering staffs, a pre-survey was then conducted. This survey was intended to understand, before the official commencement of the program, the level of ICT use by the students and their willingness to adopt ICT for their academic setting. The results indicated the high rate of technology use by the students, and hence the DoE's management allowed the project to be piloted for the first academic year 2017-2018.

For the first year, only one course was chosen. Out of the course's ten classes, only three classes were selected to be blended. The main technologies used for these blended classes were Schoology and Google Classroom, both of which are free online applications that allowed teachers and students to upload the document, and share ideas, feedback, quizzes, and assignments. While there was no specific unit assigned to deal with technical challenges, 3 management members were tasked to work in pair with the 3 volunteering faculties so that they could give each other support when problem occurred. On top of this, the rest of the faculty members, including the head of the 
department, also stood ready to give all types of other supports to both the faculties and their students. Their supports range from giving direct answers to technical questions, sharing technological know-how, to peer-to-peer training on specific issues being faced during teaching and learning process. In addition to offering spontaneous responses to issue arising during the teaching and learning process, the DoE has always spent it annual meeting to deal with a range of issues. It was during this session that challenges were raised and dealt in team.

At the end of the pilot project-the first two semesters, 71 recipient students from the three classes, who participated in BL in the academic year 2017-2018, were asked to complete the survey to assess their BL. Results proved to be quite positive, showing their positive perception towards the new teaching method or change. With promising results, DoE allowed the BL to be replicated to ten classes in the second year, and to twelve classes in the third academic year (2019-2020). To meet this growth, seven more staff were injected into the program, making total number of staff to ten by 2019. The expansion certainly marked a level of success although it was still too early to be amplified.

\section{THEORETICAL REVIEW AND FRAMEWORK}

In late 50s, discourses on change management focused exclusively on 'type' and 'process' of change (Som et al., 2020a). Most notable of all was the 'planned change' type of Kurt Lewin (1951) which dictated a top-down flow with three-step process, known as unfreezing, act and move, and refreezing. Although the theory faced subsequent challenges (Bamford \& Forrester, 2003), it is still a common practice for change management in many contexts (Burnes, 2004; Hossan, 2015), especially in the developing countries.

'Emergent type' of change was introduced as a consequence by Kanter et al. (1992), and Kotter (1996) to replace the old school of 'planned change', and to pave a more practical way for managers to manage effective changes. Center to this new theory was the argument that change in the current time takes place so sudden (triggered from external and internal factors) which do not allow managers to preplan at all. This required the institution to be open for 'emergent strategies' that equip ground staffs with all the capacity to deal with changes at their fronts (Bamford \& Forrester, 2003). Judson's (1991) five-phase to manage change was therefore built to compromise the two contrasting takes (planned and emergent). Largely influenced by Lewin's take, this theory also acknowledged the emergent nature of change (bottom-up) while also limiting the numerous steps proposed by modern theorists. To Som et al. (2020a), Judson's process was practical not only with the current change context, but also tolerable for all the earlier school of thoughts.

Planned change is also being challenged for its broadness. To the modern theorists, the three-step guideline offered too large a flexibility to managers to mitigate change, and were only applicable for small-scale and incremental change (By, 2005). In dealing with bigger scope of change, a much more directive and practical theory is needed (Appelbaum et al., 2012). Neither reject, nor agree to the above takes on 'type' and 'process', contemporary theorists including Bridgman and Willmott (2006), Orlikowski and Yates (2006), Anderson and Anderson (2011) looked at change methodology from the perspective of 'elements.' To these theorists, 'harmony' among human, technology and strategy elements in the management of change is critical. For a successful change to happen, change managers must factor in the right human resources for the change. With potential human, good strategies must be in place. Given current change is fast, technology should also be employed to put change under control. Only when these three elements work well together shall a successful change be attainable.

Seeing continued relevancy and usefulness of all the above takes, Som et al. (2020b) in their recent work on conceptual review of change management, put all those discourses in the same package in an attempt to build a common framework to manage change. According to the authors, change managers, to manage an effective change, must factor in [all] those three managerial aspects of 
change. These include the considerations of type, process and the elements. All these aspects must work together to ensure a positive change. To put it simply, there is of course no specific room for them to accommodate only one or another, but all together. On top of these important managerial constructs, Som et al. (2020b) also advanced earlier take on 'type', citing By's (2005) work on the various change types determined by rate of change, scale and how the change comes about. Advancements were also made to the earlier takes on 'process' and 'elements', detailing each of them for possible measurement.

Reflecting the two cases against the theoretical framework, it has confirmed the conceptualization of a change management framework formed by three main managerial constructs. These include change type, change elements and change process. These constructs have respectively been proposed by By (2005), Orlikowski (1996) and Judson (1991). Each of these theories is elaborated as follows:

The study on public HEIs' management of change should begin with identifying type of change as informed by By (2005). Understanding type of change would enable managers to anticipate the target and prepare the strategies accordingly. Based on the situational analysis with the two cases of Cambodian HEIs, it is understood that the change types of these cases are kind of continuous and incremental in terms of its rate of occurrence; comes in blended nature between planned and emergent; and appear in the scale of fine-tuning, incremental adjustment, and departmental transformation.

Given the specific context of the public institution in Cambodia, understanding the actors in HEIs is another focal point to be analyzed. Key actors in Cambodian HEIs are the advisory and academic board members, and rectorate, followed by the deanery, departmental team and supported by lecturers and the technical team. A strong leadership from the top and middle managers and linkage from one level to another are necessary to maintain the progress and ensure the effectiveness of the management in the institution. Losing connection and support at any level would impede the change management success. In addition, key actors have to deal with embedded aspects such as culture, roles and responsibilities, trust, and resistance which are inevitable (Appelbaum et al., 2012; Kotter, 1996; Rashid \& Rahman, 2004). A strong leader would be the one who can cope with such challenges and ensure the accomplishment of the change initiative.

Following the strong leadership and role and responsibilities, change actors must be supported by clear change process. Change process is defined as the steps for making change identifying what to do first and next. This will serve as the guide for change agents to understand the clear path and keep tracking the change project. This change process can begin either from the top, middle or the low level one, depending on the initiative of change actors. The review on the literature of change models and process has informed step-driven model proposed by Lewin (1951), Kotter (1996), Kanter et al. (1992), and Judson (1991).

As argued earlier, the 3-step change of Lewin is known as too broad giving too much freedom and for managers to execute change and guideless to novice managers to follow. The nature of this process is sort of planning and domination from the top leader, which does not really imply the leadership in the current situation. Also, the eight and ten steps change of Kotter and Kanter are too rigid demonstrating many steps to follow, while missing any steps could make the change failed. These theories, likewise, aim to control practitioner's flexibility and strategy when executing change. Hence, selecting one change process that is in between the two could be a choice. The Judson's 5-phase model based on its relevancy to the change context at the IA and the DoE of IB that the study has done as the situational analysis, and with neither too many nor few stages to be implemented, is selected as a part of the change process of the conceptual framework. This model includes these following steps: (1) analyzing and planning the change; (2) communicating the change; (3) gaining acceptance of new behaviors; (4) changing from the status quo to a desired state; and (5) consolidating and institutionalizing the new state. 
Within each step, Judson's process allows flexibility and strategic change for managers to manage with their respective skills and tactics, while achieving the goals of each step is the ultimate target. In addition, while following the process of change, it is prudent to take change/supporting elements into account that include human, technology and the strategy (Anderson \& Anderson, 2011; Orlikowski \& Yates, 2006; Som et al., 2020b). As stated above, human element is embedded with culture and that which heavily determines one's behavior and attitude. The literature review on the culture in academic institution informs that collegial culture is one of the most conducive practice to change program (Kezar \& Eckel, 2002; Rashid \& Rahman, 2004). Any workplaces that embrace such culture would allow managers to implement the change with ease. Meanwhile, a leader that is trustworthy could communicate the change with the staff easier that that others (Alas \& Vadi, 2006). Beyond these skills, leaders that have the ability to manage human resources, divide roles and responsibilities, deal with resistance, seek for funding from external partners, exert the benefits from technology use, are the key person to make the change successful.

Change to BL could not be done without the complement of technology. This construct in this sense can be grouped into tools, skills and system (Som et al., 2020b). Technology literally refers to what tools that are being used, why it is selected over the others, and how beneficial is it. Introducing new tools would require capacity development or training for staff on how to use which can be done in different ways depending on the management strategy. Moreover, technology plays a role as an ecosystem of which the use of one tool requires the other tools to support and to make the system workable. For instance, the use of LMS would not be possible without the support from the internet access, smart devices and IT support team.

Strategy is known as another element or quality that cannot separated from change management. This is the free tactics used by manager to dictate the change and make each step of change process possible. Burnes (2009) asserted "rather than managers being the prisoners of mathematical models and rational approaches to strategy development, they have considerable freedom of action and a wide range of options to choose from" (p.246). Open participative communication, direct communication, persuasive communication and message redundancy strategy, to name a few, are the example of the key strategies being used by managers when communicating the change for gaining acceptance. Other strategic changes may be used differently depending on individual manager. From the above presentation, a conceptual framework for the management of the change at both IA and DoE of IB can therefore be drawn as shown in figure 1 below.

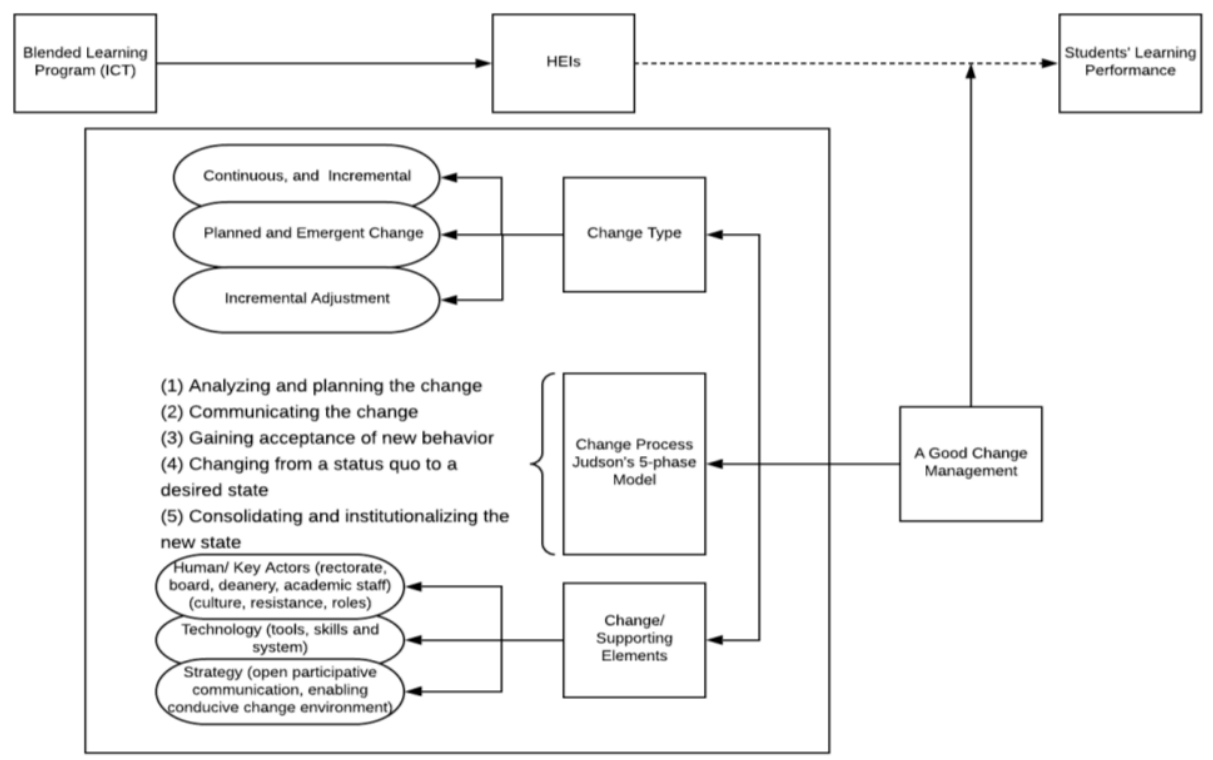

Figure 1. Conceptual Framework

Source: Authors 


\section{METHODOLOGY}

To investigate the change management practices (BL adoption) at two leading HEIs in Cambodia, and to reconfirm the framework of change management that works, this study followed qualitative approach and adopted case study design for data collection. Due to little prior research in this field, particularly in Cambodia, a situational analysis was conducted to understand the context of the cases better. Amidst situational study, researchers had reviewed internal report and discussed with several key managers of both institutions. Following this, a list of questions was constructed as guided by the literature and early field work for individual interviews and focus group discussion.

Academic staffs ranging from university rector/director to dean, department management team and teaching staffs at the two HEIs were the key informants in this case studies. Because of close relationship between researchers and the management team of the two institutions, the interviews were conducted without much obstacles. Firstly, researchers sent two official letters to respective institutions requesting for conducting research. Then, researchers approached the top and middle management, namely deputy director/vice-rector of the institution, or heads of key departments for individual interview before seeking their suggestions for other resourceful informants, as a snowball sampling technique. It worth noting that researchers had sought for consent from each participant prior to the interview and focus group. Each participant could reject voice recording and not to answer any sensitive questions.

Researchers had no prerequisite number of participants for the interviews. The fieldwork was stopped once new information could not be found from participants (data saturation point). In total, eighteen key informants (denoted as I1-I18) from both IA and IB, and other relevant bodies had been interviewed (appendix). Nine lecturers (denoted as P1-P9) from different departments under the IA were also formed into a group for a focus group discussion. The result from this field work was later translated and transcribed manually, before it was categorized into themes for presentation.

\section{FINDINGS}

At both DoE of the IB and IA, changes are managed with a serious consideration of type. They all get started from small scale. At DoE, only three classes, out of ten classes in a writing program were selected for the BL program, so was at the IA where change program was introduced to only one of its eight department before expanding to all the departments. On top of this, the expansion of the change program at both institutions are found to be incremental. Over its consecutive successes, BL program at the DoE was expanded from three classes in 2017 to all the ten writing classes in 2019. At the IA too, incremental expansion was made to all the eight departments in 2015 following its successful program piloted at the GIC in 2012. As for 'how those [change] initiatives came about' was found to be a mix of bottom-up and top-down flow of intervention. While BL program was said to be initiated by a group of lecturers back to 2006 under the GIC, there was no evident to prove that it happened without the knowledge of top management. In the interview with the Deputy Director of the IA, he expressed his knowledge of the so-called program although he was not stating any obvious top-down intervention. Likewise, blended learning at the DoE was also said to have been initiated by a group of lecturers of a writing program. Although they denied top management involvement, the knowledge of program existence was also confirmed by the DoE head who also claimed an extent of IB's top management support for participating lecturers at the DoE. That was why calling those initiatives as purely "emergent" is not appropriate for the conditions at IA and IB where top management were in hard position to initiate change given the limited resources they had in hands. 
As for the element of changes, serious considerations of human, technology and strategies are obviously seen in both cases. Regardless of the DoE where these elements were not that substantial for full-length analysis, tactical employment of these elements were found at IA. To prepare for the BL program, some sixty staff were sent by top management for training abroad. Upon their returns, these staff helped other staff to convert their regular program into BL program. With able staffs, IA top management readied up technical facilities for them to work with. These included setting up the studio and recording rooms, offering an in-door 5G intranet connection, and tasking technical support teams to troubleshoot any technical challenges faced by students and lecturers during the course of BL adoption. To ensure that human elements were working harmoniously with technology, several strategies were devised to support the program. These included volunteering strategy, peer-pressured strategy and DoE's pairing strategy. On top of these specific strategies, tactical efforts to mobilize resources and to create enabling environment for change in general were also found to have been widely employed by the IA top management and by the middle management of both the Center and DoE. Aside from these many findings, another remarkable one is on the fact that IA's top management, though relinquishing certain authority to middle managers, is still having a big decision on the elements of change. While this could arguably be considered as "power struggle" between the Center head and top management, it could be viewed otherwise as top management strategy to help create an "enabling environment for change" in the context of Cambodia.

Unlike type and elements whose decisions were mainly made by top management, decision on 'process' to manage change is seen to be fully delegated to the Center's authority. Little evidence suggested that top management at the IA proposed any specific process to manage change, so did their direct interventions on the day-to-day change management at the Center. This gave the Center almost a complete power to manage change under their own authority. In-depth interviews with former and the current heads of the department, deputy heads, lecturers' representatives from a focus group discussion suggested that middle managers were the ones to identify change priorities (the conducts of feasibility studies at the DoE to gauge the possibility of program success and the mid-term reviews conducted by both the DoE and the Center to assess the level of success) and to communicate those priorities to staff on the ground and management at the top. They acted as both program managers and messengers to ensure that change priorities were taken by both echelons. On top of these, they were the ones to make sure that those priorities were accepted. Remarkable "acceptance variables" were drawn out of the findings which included study background, age, working status, financial incentives, peer success stories, ease of use and perceived usefulness etc. With different acceptance level varied along the found variables, overall change programs at both the IA and IB were rated to be successful given the increased student satisfaction and participation, increased lecturer involvement, and the continued program expansion to local Higher Education Institutions.

Despite the above optimism, ability to move the success from the status quo to any desired state, and to fully institutionalize the change at IA is still largely questionable due to a number of reasons. First is the perceived future uncertainty caused by institutional financial constraint. Even overall capacity for change adoption looked just fine once asked further if he was optimistic that the program could sustain itself, a lecturer in focus group expressed doubt on this. So long as many of what available - technical equipment, studio maintenance, development of course materials etc.were all still financed by the partners, the future of this change program was certainly unpredictable. While common goal was found to be an entrance to change participation, continuous financial support helped to ensure that staff adoption of BL lasts and the success sustained through time. An extent of setback is being felt at the IA as fund from ACU project came to an end. According to a lecturer in the focus group, no new recording was being made when funding from ACU project is dying down. Many of what being used were old lessons recorded a few years back (P1, P3). This same challenge was also admitted by the Head of the Center who were not very 
optimistic of ability to institutionalize change at face of this financial constraint. "And if there's no [financial] support to the respective university, you know what's going to happen! They will do it [just] for a while and stop." (I5). To the Head, institutionalize change was still far-fetched given the limited amount of budget the IA has: "Err...overall we expanded, but if we want BL to be implemented in every course, it's going to be very hard. Each converted course cost around $\$ 4,000$ to $\$ 5,000$, and we have around a thousand courses in total (I18). For its future to be more certain, the institution needed to think of strategies to sustain this success in a much longer run, he further added.

Second, although it was understood that various attempts were made by top management at IA to support the changes at the Center, a lack of strategic and systematic support from the top is predominantly seen to be the cause of stagnation to move the achieved success to a desired state. Some supports thus far were claimed to have missed the prioritized targets, or even unresponsive to the real needs on the ground:

"Err...the university has a very big vision but the support it gives is not yet right. With eLearning Center, we could produce the contents. But with contents alone is not enough. We have to meet course developers, technicians and other 3 units for a complete set. With only one studio and one course developer at the moment, we just cannot build that quick. We need top management support." (P1).

Deputy director admitted this, claiming supports for the change project was still largely selective and based on the available resources the institution had. "But the term 'fully support' is based on the budget too... if the investment is bigger than our capability, we cannot afford it.

Third, lack of effective monitoring procedure is found to be another critical challenge to move the success (at the Center) to a robust desired state. Although regular meetings were conducted, a real mechanism to monitor progress was not in place. Available communication channels, in addition, were filled by unnecessary information, undermining their critical roles to offer an effective platform for monitoring and evaluation. A participant in the focus group used a metaphor to liken an absence of monitoring procedure at IA to tree planting without watering and fertilizer. "Without top management monitoring, many of instructional videos are becoming less relevant or even obsolete". To revise the contents, they needed to undergo many difficult processes (meeting with three or four teams at e-Learning Center) which they thought not worth it (P1). All the participants in the focus group came up with common request for frequent monitoring from school level, without which they were less optimistic that the program was going to be successful in a longer run. (P2) "Frequent monitoring is indispensable. No matter how hard the Center tried, if staff are left unchecked, the program is doomed to fail".

Last but not least, role of middle managers is truly indispensable for change success. It was absolute undeniable that success at the Center had largely been contributed by painstaking efforts of its Head and deputy Heads. It was however not the case of other departments under the IA. Many of those heads were reportedly less active, making the attempt to move the achieved success to any desired state at the institutional level hardly possible. A lecturer in focus group confessed that he did not join the program because he got no encouragement from his department head. Many other lecturing staff, despite not showing direct objection, did not involve in this change project. They claimed their respective management heads were not effective and unsupportive (P1,P3,P5,P9). "Of all the eight departments at the IA, only some twenty-four courses have so far been converted to BL. This small number demonstrated the limited staff participation in the change program" (I6). Had there been many potential middle managers or head of departments that are committed to the change as the head of e-Learning Center and GIC, then the adoption of BL at the IA would have achieved much satisfactory results than this. While moving change acceptance to any desired state at IA is hardly achievable, this condition is far worse at the IB. Biggest of all was the absence of top management supports to change initiative at the department level. I2 expressed doubt for the future of his change program at the DoE: 
"I accept that we are successful... but I doubt for its long run; we need the support from top management... our situation here is completely different from that of the IA where system and technical support were granted from top management; here, everything has to be done by teacher themselves... if we talk about university wide support, we don't have it yet"

On the financial front, resistances grew from staff who had long been using their own money to afford technical tools and internet connection. "The internet is too slow, or even not working; we therefore needed to use our own hotspot," I12. To the best the department could do was giving those staff small sponsorship package to join local conferences (CamTESOL) and some opportunities for oversea studies and conferences. On technical front, participating staff at DoE felt helpless as staff had to work among themselves to deal with technical challenges. The IT Center which was supposed to assist on technical challenges did not function, dropping technical trouble shootings and technical trainings to the shoulder of individual staff and the department. "Regardless of the slow internet connection, we didn't get any technical supports from the institutional level. Therefore, we can hardly call this class as BL because we don't have updated technical equipment" (I12). It is highly that, if the situation remained, the BL at the DoE would experience setback, admitted I12.

Despite some differences as earlier mentioned, common to both IA and IB was the absence of supporting policies. A push for institutionalization of change is totally impossible shall policies are not effectively enforced. Many respondents pointed to policy challenges as the cause of their program setbacks (P1, P5, I1, I12, I10). This challenge was even more obvious for both the IA and IB where volunteerism was still used as a main strategy to buy people into the change program. By far, the IA, despite a considerable success, has yet to enforce any effective policy to push for change. Most of the practices were guided and driven by [oral] agreement between the management team and lecturers (I5). Nonetheless, Head of the Center agreed that school policy was important shall a program be intended for institutionalization. "In case we want to apply BL institution-wide, we definitely need policy supports from the Director. Without it, we can never institutionalize it (I5). At IB too, policies to support change were not available. An obvious example of the failure of BL program at the Department of Engineering (DE) was said to have been caused by the absence of policies to encourage students and lecturers to join the program. Without such enforcement, both students and lecturer took BL less seriously and opted to keep their status-quo (I1). To implement a successful change, both institutional policies and strategic planning are needed. "If we don't have these two, we don't know where to go", I11.

A general conclusion could therefore be drawn from the above findings that changes at both IA and IB were managed accordingly with the constructed framework. Despite remarkable success at the IA and IB, a number of other challenges were however identified to have thwarted the attempt to move BL program to a desired state. These included the future uncertainty of the program which have been caused by financial constraint, unsystematic and strategic supports from top management, ineffective monitoring system, and inactive middle managers. Central to the above challenges was seen to have been caused by the lack of right and consistent supports from top management, and the absence of supporting policies which caused both the IA and DoE far from being able to institutionalize the change.

\section{DISCUSSIONS}

When role of managers in change is discussed, two schools of contrasting thought concurred. To the thought of the first school, middle managers' role is less important than top managers' whose decision was in many ways influencing the level of support provided by the functional managers (Muluneh \& Gedifew, 2018). Against the above thought, Bamford and Forrester (2003) claimed that roles of top manager are less important, compared to that of the middle managers. The case of change at the IA however seemed to contradict these thoughts, pointing to the criticality of both 
roles in managing the change. It was reported that although the proposal was developed at the department level, final decision on scale, scope and certain activities of the project rested in the hands of top managers. This planning role is of no surprise for a developing country, like Cambodia where decision-makings are still depending on the approval from top authority. Not only does the practice of pre-planning exist in developing countries, Australia, which is noted as a well-developed nation, is still found to be centralized in its own way in terms of decision making, particularly in the governmental county working process (Hossan, 2015).

Despite the contradiction, starting change from a small scale and at an incremental rate were well in congruent with the mainstream theories, particularly with that proposed by By (2005). At both IA and DoE of the IB, change started from small scale. While this cannot be confirmed if it was a 'change management' methodology, it could also be interpreted as an ability to match the scale of change with the capacity of change team available on the ground (I5). The selection of the Department of GIC alone to pilot the program was because the GIC had substantial experiences in using the BL since 2006. Only when an extent of success was achieved was the program allowed to be replicated to all the 8 departments, and exported to other public higher education institutions in the country.

Elements of change, namely human, technology and strategy, were also found to confirm the relevance of change methodology at IA with that of mainstream theories. In spite of nuances, these theories pointed to the considerations of human, technology and strategy in the management of change (Anderson \& Anderson, 2011; Bridgman \& Willmott, 2006; Orlikowski \& Yates, 2006). At its official start in 2012, some 60 staff at IA was dispatched for training abroad. Technologies needed for change were, at the same time, built (the studio room, recording room, staff common rooms) to accommodate returning staff for the change project. Strategies by both top management and middle management were also developed to pave ways for smooth operation. Nonetheless, numerous complaints were also reported, including, but not limited to the lack of strategic supports from top management, an absence of monitoring and evaluation procedures, a total dependence on external funding etc.

While the above complaints were caused mainly by a serious lack of strategic supports for change on the ground, it was also said to have been caused by the misinterpretation of change management by institutional leadership (Khan et al., 2012). "Change management" involves the projection of inclusive strategies - curtailing human, technology and strategy elements to meet with projected scale of change through a controlled process - to deal with change. These three elements have to be symbiotically related (Orlikowski \& Yates, 2006), and reciprocally related to one another to produce a positive change. Short-term results would be achieved (Kotter, 1996), while increasing instability instead of reducing it, if there was a one-side intervention on any of these two variables. When asked to what extent change was being managed at the IA, Head of the Center said he didn't manage any change. Although most of what he described fall into many aspects of change management, he failed to emphasize how he makes those aspects (human, technology, strategy) work harmoniously together to ensure that the result of change is what the institution wishes for. This misconception on change management mirrored the fact that change has been, on the one hand, managed on a reactive basis (mere problem solving), it, on the other hands, exhibited an ineffective strategy to manage change (Muluneh \& Gedifew, 2018). Only with a clear understanding of change can a business properly prepare them to deal with the new challenges arising from sudden shifts in the world economy and in the nature and content of knowledge itself (Drucker, 1997).

Drawing together both type and elements of change, it was found, on top of the above challenges, that top management at IA inserted quite excessive control on the decision of type and elements of change. Although it was acknowledged that a mix of bottom-up (emergent) and top-down (planned) intervention at the IA worked literally well for the context of Cambodia, clear roles and responsibilities between top and middle management must be drawn. While there is such division 
found at the IA, such roles and responsibilities were not enough yet to ensure the right functioning of change agents. According to Bamford and Forrester (2003), top managers, though having the overall responsibility for effective change, were not supposed to plan or implement change, but only to create an environment that was conducive to experiment and risk-taking, and to develop a workforce that would take responsibility for identifying the need for change and implementing it. Middle managers, according to Bamford and Forrester (2003), are the one to lead the change effort. According to I5, his idea (to start the program a bit bigger than just the GIC) was rejected by top management. The expansion was only agreed when an extent of success was proved in 2015 . Far more problematic was the fact that the creation of taskforce for change, and decisions to build up technology supports at the Center was also influenced by top management. In fact, these roles were supposed to be played by middle managers who directly faced the change, knew well the change team, and what technical supports needed for change at their ground level.

Even with these change factors, effective change relies heavily on the process. Bringing together "Ten Commandments for Executing Change" (Kanter et al., 1992), "Eight Stage Process for Successful Organizational Transformation" (Kotter, 1996), "Seven Steps to Change" (Luecke \& Luecke, 2003), and "five-phase model" to manage change (Judson, 1991), one should never disregard the indispensable role of middle managers to manage the change. As the ones to face change, these managers were obligated with a critical role to mitigate the whole process of change. This criticality is well reflected in the case of DoE where success was attainable even at a complete absence of top management support. From identifying key change priorities, to communicating those priorities down to ground staff, and having them accepted, middle managers at both the IA and DoE were able to bring about an extent of success to their respective institutions. This came, however, not without a challenge. Head of the DoE expressed doubt about the future of his change program at the continued absence of top management supports, so did the Center Head who found no place to get the Center's success institutionalized. While this limitation is caused on the one hand by institutional hierarchy (I5), it, on the other hand, pointed out the reason of Judson's acceptance of Lewin's take on the top-down intervention by top management. With top management support, impact is bigger, to simply put (I11).

In sum, although change methodologies adopted by both IA and DoE of the IB are well in congruent with the constructed framework, and an extent of success was achieved, moving change to a desired state or even institutionalizing it is still largely questionable. "It was successful at one point, but I don't think it is 'institutionalized' yet", I3. To deal with this, top managements, particular at IA, should lessen its control on type and elements, leaving this authority for the Center head to tackle them from the Center level. Top management should instead be focusing more on offering strategic supports to middle managers, particularly when supports are needed to move an achieved success to any desired state or to institutionalize it once and for all. Supports, in this regard, include the provision of practical policies, the allocation of sufficient institutional financial resources to support change, and the establishment of a reliable monitoring and evaluation system to oversee the overall progress of change program.

\section{CONCLUSIONS}

A conclusion could therefore be drawn to confirm that the established framework does represent the real practices of change management at both the IA and IB. Change (the adoption of BL) at both the IA and IB took into serious consideration of change type, elements and process. While top management at IA tended to insert more control on the decision on type and elements of change, it relinquished a great amount of power to middle managers to manage the 'process' of change. This (tighter) control, on the one hand, could be seen as challenges for middle managers to manage change on the ground (Center level), it could, on the other hand, be interpreted as a top management's strategy to create a "favorable environment" for change. An extent of remarkable 
success is achieved out of this practice although it could be short-lived, should top management (at IA in particular) fail to lessen their control on change type and elements, and instead focus more on giving the right supports to change team. Right supports herein entails a refocus of top management on the supports it must give to ground managers to institutionalize change by means of providing adequate finance support, practical policies and a consistent monitoring and evaluation.

\section{ACKNOWLEDGMENT}

This paper is part of publication requirement for a Ph.D. degree of the above corresponding author. Focusing on "the ICT-driven change and its management", the author has published a number of scientific papers in both international and local journals and international conference proceedings. Specific to this paper, the author wishes to acknowledge the supports from top management and staffs from both the IA and IB without whose supports this paper cannot be materialized. Another special acknowledgement is also made to Prof. Danut Dumitrascu of Lucian Blaga University of Sibiu who, in his capacity as a principal supervisor to the author, has played his very active role to support the cause. Last but by no means least, special thank is given to all the organizers of the forth-coming IMC-2021 conference who leaves room for the author to have this paper published as a conference proceedings.

\section{REFERENCES}

Alas, R. \& Vadi, M. (2006). The impact of organisational culture on organisational learning and attitudes concerning change from an institutional perspective. International Journal of Strategic Change Management, 1(1-2), 155-170.

Anderson, D. \& Anderson, L., A. (2011). Conscious change leadership: Achieving breakthrough results. Leader to Leader, 2011(62), 51-59.

Appelbaum, S. H., Habashy, S., Malo, J.-L., \& Shafiq, H. (2012). Back to the future: revisiting Kotter's 1996 change model. Journal of Management Development, 31(8), 764-782.

Bamford, D., R. \& Forrester, P., L. (2003). Managing planned and emergent change within an operations management environment. International Journal of Operations \& Production Management, 23(5), 546-564.

Bridgman, T. \& Willmott, H. (2006). Institutions and technology: Frameworks for understanding organizational change-The case of a major ICT outsourcing contract. The Journal of Applied Behavioral Science, 42(1), 110-126.

Burnes, B. (2004). Kurt Lewin and the planned approach to change: A re-appraisal. Journal of Management Studies, 41(6), 977-1002.

Burnes, B. (2009). Managing change: A strategic approach to organisational dynamics (5th ed.). Prentice Hall.

By, R., T. (2005). Organisational change management: A critical review. Journal of Change Management, 5(4), 369-380.

Drucker, P. F. (1997). The future that has already happened. Harvard Business Review, 75(5), 2022.

Franklin, T., J. (2015). Embracing the future: empowering the 21st century educator. ProcediaSocial and Behavioral Sciences, 176, 1089-1096.

Hewitt-Taylor, J. (2003). Technology-assisted learning. Journal of Further and Higher Education, 27(4), 457-464.

Hossan, C. (2015). Applicability of Lewin's change management theory in Australian local government. International Journal of Business and Management, 10(6), 53.

Judson, A., S. (1991). Changing behavior in organizations: minimizing resistance to change. Blackwell Business. 
Kanter, R., M., Stein, B., A. \& Jick, T., D. (1992). The challenges of execution: roles and tasks in the change process. The Challenge of Organizational Change, 369-394.

Kezar, A. \& Eckel, P., D. (2002). The effect of institutional culture on change strategies in higher education: Universal principles or culturally responsive concepts? The Journal of Higher Education, 73(4), 435-460.

Khan, M., S., H., Hasan, M. \& Clement, C., K. (2012). Barriers to the introduction of ICT into education in developing countries: The example of Bangladesh. International Journal of Instruction, 5(2), 61-80.

KOICA. (2014). Cambodian ICT masterplan, 2020.

Kotter, J. (1996). Leading change. Harvard Business School Press. https://books.google.com.kh/books?id=ib9Xzb5eFGQC

Lewin, K. (1951). Field theory in social science. Harper.

Luecke, R. \& Luecke. (2003). Managing Change and Transition. Harvard Business School Press. https://books.google.com.kh/books?id=szFFsHufKuAC.

MoEYS. (2010). Education strategic plan (2009-2013). Ministry of Education Youth and Sport.

MoEYS. (2019). Education strategic plan 2019-2023. Ministry of Education Youth and Sport.

Muluneh, G., S. \& Gedifew, M., T. (2018). Leading changes through adaptive design: Change management practice in one of the universities in a developing nation. Journal of Organizational Change Management.

Nyandiere, C. (2006). Increasing role of computer-based information systems in the management of higher education institutions. Proceedings of the Annual Strathmore University ICT Conference.

Orlikowski, W., J. \& Yates, J. (2006). ICT and organizational change: a commentary. The Journal of Applied Behavioral Science, 42(1), 127-134.

Poon, J. (2013). Blended learning: An institutional approach for enhancing students' learning experiences. Journal of Online Learning and Teaching, 9(2), 271-288.

Rashid, M., Z., A. \& Rahman, A., A. (2004). The influence of organizational culture on attitudes toward organizational change. Leadership \& Organization Development Journal, 25(2), 161179.

Som, R., Chan, R. \& Dumitrascu, D. (2020a). Conceptualizing a framework: A critical review of the development of change management theories. Studies in Business and Economics, 15(2), 205-214.

Som, R., Chan, R. \& Dumitrascu, D. (2020b). Understanding type, process and elements of change: A conceptual review on the framework of change management. The Poceedings of the 14th International Management Conference, 487-496. https://doi.org/10.24818/imc/2020/03.01

Tusubira, F. \& Mulira, N. (2004). Integration of Information and Communication Technology in organizations: Challenges and best practices recommendations based on the experiences of Makerere University and other organizations. A Paper Presented at Hotel African Kampala Uganda from 5th to 8th September.

Wheeler, S. (2001). Information and communication technologies and the changing role of the teacher. Journal of Educational Media, 26(1), 7-17. 


\section{APPENDIX}

\section{List of Interviewees}

\begin{tabular}{llc}
\hline \hline No. Informant & Position & Interview Date \\
\hline \multicolumn{2}{c}{ In-depth Interview and Focus Group } \\
\hline 1. Informant 1 & Head of Department (FE/IB) & $06 / 10 / 20$ \\
2. Informant 2 & Head of Department (DoE/IB) & $19 / 10 / 20$ \\
3. Informant 3 & Deputy Head of Department (DoE/IB) & $20 / 10 / 20$ \\
4. Informant 4 & Vice-rector/Deputy Director (IA) & $20 / 10 / 20$ \\
5. Informant 5 & Head of Department/ Head of the Center (e- & $20 / 10 / 20$ \\
& Learning Center, IA) & \\
6. Informant 6 & Deputy Head of Department (GIC, IA) & $20 / 10 / 20$ \\
7. Informant 7 & Head of Department (Foundation Year, IA) & $21 / 10 / 20$ \\
8. Informant 8 & Lecturer (IA) & $21 / 10 / 20$ \\
9. Focus Group 1 & A Group of Lecturers (IA) & $21 / 10 / 20$ \\
(9 Participants-denoted as P1-P9) & \\
10. Informant 9 & Head of a Center (IT Center, IB) & $22 / 10 / 20$ \\
11. Informant 10 & Lecturer (DoE, IB) & $24 / 10 / 20$ \\
12. Informant 11 & Lecturer (FE, IB) & $24 / 10 / 20$ \\
13. Informant 12 & Lecturer (DoE, IB) & $24 / 10 / 20$ \\
14. Informant 13 & Director General of the General Department & $07 / 11 / 20$ \\
& of Higher Education (GDHE), MoEYS & \\
15. Informant 14 & Head of Department (IA) & $13 / 11 / 20$ \\
16. Informant 15 & Lecturer (GIC, IA) & $13 / 11 / 20$ \\
17. Informant 16 & Head of Department (IT Department, IB) & $16 / 11 / 20$ \\
18. Informant 17 & Vice-Rector (IB) & $16 / 11 / 20$ \\
19. Informant 18 & Former Head of the center (IA) & $24 / 11 / 20$ \\
\hline
\end{tabular}

Note: Head/Dean does not necessarily denote the head of an institution; it can be a Deputy Head/ Vice Dean. 